Available for free online at https://ojs.hh.se/

Journal of Intelligence Studies in Business 2 (2012) 51-57

\title{
An evaluation of Business Intelligence Software systems in SMEs - a case study
}

\author{
Mattias Nyblom, Jenny Behrami, Tung Nikkilä, Klaus Solberg Søilen* \\ *(Corresponding author), Halmstad University, Box 823, 30118 Halmstad, SWEDEN \\ E-mail: klasol@hh.se
}

Received February 5, revised form 10 May, accepted 25 May 2012

\begin{abstract}
This article proposes a simple model for evaluating the performance of Business Intelligence software systems based on what companies themselves find to be most important; efficiency, user friendliness, overall satisfaction, price and adaptability. Companies want to know the different systems used, why they are used and how effective they are for different tasks. They are also concerned about the systems' compatibilities. The study builds on a deep interview with eight Swedish SMEs. The results show what terms are used by users, how they have solved their information needs and what problems arise in each company. It also shows that the decisions about what system to use are related to the experience specific individuals have had in other companies.
\end{abstract}

KEYWORDS: business intelligence, software systems, business analysis, decision support

\section{Introduction}

In today's competitive environment companies" "Business Intelligence software systems" have become a central concept. In the fierce competition that exists, it is important for a company to have efficient and effective software systems to collect, process and store data of various kinds. For example, you have to have a good system for customer management finance and so on. However, today there are so many different systems for these tasks that it has become important and meritorious for companies to handle the differences between these different systems. It is important to know what Business Intelligence software system is, which different systems that are used and how to use them. In this article we have chosen to examine these issues more closely by going in depth with the concept of Business Intelligence and examine how a few different companies use them, to bridge a gap between theory and practice.

Business Intelligence is a general term for a variety of functions that support effective decision making within a company. In Swedish, we often call it business analysis (affärsanalys) or decision support (beslutsstöd). The most common terms usually used in Business Intelligence are market analysis, environmental analysis, customer analysis, data mining, Business Activity Monitoring and competitor analysis. The foundation of business intelligence is to have access to right information at the right time for decision makers in order to make the right decision. It is therefore important to have effective systems that can help the company to collect, store, compile and process data in different ways. Such a system is called business intelligence software system. Sabanovic and Solberg Søilen (2012) have previously examined companies' 
expectations and need in terms of Business Intelligence systems.

Companies have long used various business intelligence software system but these have never been so numerous, extensive, and advanced as today. This is also likely to continue, so that the technology tested here in this article will soon be outdated. An evaluation model however can be useful over time. It is important for companies to know about the different systems actually used today to find the system that best suits their business. There are reasons to believe that there is a discrepancy between theory and practice in this field, between what companies actually use and what the textbooks suggest they use. This is a particular problem for SMEs who do not have the resources to purchase tailor made business intelligence solutions. We also want to know why they are using the systems they have in place.

\section{Method}

This study started with a different purpose than it has now. The work began as a comprehensive survey of Business Intelligence Software Systems. The aim was to make a quantitative survey where we would get answers on Business Intelligence Software Systems from 50 different companies and then generalize and make conclusions. We began the study by sending out a questionnaire by mail to 274 companies. The companies were selected by a random generator that randomly selected 274 companies independently of their size, geographical location and industry (http://www.slump.nu/). The reason we decided not to have limitations of our sample to industry, geographic area or company size is because we believe that all the above factors have little or no impact on the research and the answers we wanted to get. The only restriction we had when it came to selecting respondents is that we would only contact companies in Sweden. After a while we realized that business intelligence is a diffuse area to investigate in several ways.

Firstly, the term business intelligence is relatively new in Sweden and companies have not really grasped what it is. We also reached the conclusion that it is a complex area to investigate since companies do not want to give out more information than necessary, since they suspect that this might be used to their disfavor. The answers were, in other words, difficult to obtain. We therefore restructured the entire work and instead of doing a quantitative study we chose to do a qualitative study based on a case-study method in which we examined a handful of companies in more details through deep interviews, to find out what system they use and how they experience how their system works for them based on a series of aspects.

A Case-study method is used in researches with purpose to study exclusively on a number of small selected cases (Onwuegbuzie, Johnson \& Collins, 2009). One of the goals with the case-study is to analyze and interpret attitudes and opinions from the selected sample toward a particular studysubject or object. Another aspect that we took into account when we chose a case study is its' usefulness to get answers according to matters like "how" and "why", which relate straight to the purpose of this article (Cepeda and Martin, 2005). Thus this method was suitable because we wanted to narrow down the selection of the companies and do some deeper research into their practices.

Finally, we chose eight companies to work with, Swedish SMEs. We came in contact with these companies when we did the quantitative study. In other words, we took the eight companies that were willing to answer our questions. We interviewed one person at each company and asked questions about the systems they use and how they would evaluate them. Based on their own criteria we then evaluated each one based on our conversations, in the form of deep interviews. We also compared information about the companies and the information about each system from their respective websites.

\section{Empirical Data}

We have contacted eight companies with questions about their Business Intelligence Software Systems. We have also looked more closely at what these companies are doing and how their information need looks like. Below we present the information we received in a summary:

\subsection{Company 1: Kungsäter Industri}

Kungsäter Industri has been around since January 1972. It is a company focusing on making-up, i.e. drawing, cutting, pressing and merging technical textiles to large and small products. The number of employees in the company is around 50. Most of these are in production. They manufacture products such as tents, floor cloths, door screens, covers, sheets, tablecloths and other silo solutions in technical textiles. All products are made according to customer order and customization. The company has a turnover of more than 50 million SEK a year.

The company uses a system called Pyramid. This is a business system that is designed for both small and medium sized companies in several industries. 
It is designed to be used to finance, logistics, CRM, manufacturing, e-commerce, project management and more (see www.unikum.se).

Kungsäter Industri is using Pyramid as a CRM system, for example to manage information about their customers, and process it in a flexible way. According to our contact they are using this system because they think it is easy to handle and because they do not want to venture into a more advanced system for feelings that it will take too much time, be too expensive and too complicated for their needs. The company may consider switching system in about three years if the company evolves as they hope for. Right now, they believe that they have a too small customer base for it to be necessary to engage in a more advanced system.

\subsection{Company 2: Tidbecks}

Tidbecks was founded in 1840 and has been around for over 170 years. Over the years the company has evolved with time and is today a modern engineering company. Tidbecks manufactures and supplies welded netting, welded mesh, crenellated grille, crenellated networks, customized wire products, wire mesh and stretch materials. The company has currently 34 employees in total and they have a turnover of approximately 60 million SEK per year.

The company uses a system called Monitor. This is a system that can be used in the fields of manufacturing, purchasing, sales management (CRM), warehouse, workshop information, and accounting. It is a complete business system designed for manufacturing companies (www.monitor.se). Tidbecks is using the system for accounting and customer management. They believe it is a good program where they can store all the information they have in order to compile it into various documents. The reason why they have chosen to work with Monitor is that they have previous knowledge of the program from another company where some of the staff were employed. Our contact says that they sometime in the future may consider switching system to a more comprehensive system, but they are not sure about what they will use then.

\subsection{Company 3: Evaldssons}

Evaldssons' has been around for 60 years. It is a construction company that undertakes all kinds of missions within the area of construction such as new construction, service, maintenance and repairs. They are specialists in construction, flooring, tiling and painting. The company has 30 employees and their turnover is around 35 million SEK per year.
Complementary to sell the construction the company sell materials and products needed in construction such as tiles, different floor types, boards, plates, racks and other building materials. This is sold through an online shop.

The company uses a system called Visma. This is a business system that is comprehensive and can handle many business areas within a company. Visma has a range of programs you can use depending on the company's purpose with having the system. For example, the user can use the business system for financial statements, billing, payroll, training, sales support, customer support, logistics, time, projects, e-commerce, information storage and cash solutions (www.visma.se).

Evaldssons is using the system in all its activities and have therefore a custom made concept. According to the contact, the most important feature of the system is the customer management application. The reason why the company choses to use this system is, according to our correspondent, that the program is very well-made and has been on the market for quite some time. She also states that, as VISMA-customer, you have technical support 24 hours a day and this is the best feature with the product. Despite the good qualities of the program, they do have plans to change the system in the near future. This is because they want a more internetbased system with larger capacity. She says VISMA is fine until they replace it and it has always worked for the company.

\subsection{Company 4: Cejn}

Cejn AB was founded by Carl Erik Josef Nyberg in 1955. Cejn started their business in a basement in Skövde with two employees. Carl Erik Josef Nyberg created a revolutionary quick clutch, which overcame many of the old models' deficiencies. The new clutch dramatically simplified the handling of compressed air and creates reliable and efficient connections. The invention laid the foundation for much of Cejn modern product line, and was the starting point for Cejn's commercial success in global markets. Today, Cejn has 17 sales companies, six production units, and 450 employees worldwide (www.cejn.se).

The company's design is based on small external measurements and large internal measurements. In other words, their standard couplings have high flow capacity while being robust and easy. The company supplies the global market with high performance couplings and systems for hydraulics, compressed air, liquids and gases. The company's product range also includes accessories such as adapters, hose, hose reels, air handling units, and 
blowguns. With a focus on customer satisfaction, Cejn are focusing on innovative solutions that lead to a superior product. The company's product range can be complemented with other products that meet its requirements for quality and performance (www.cejn.se).

Cejn's strength lies in their intelligent technology solutions, along with high quality and efficiency. They are developing not only what is in demand today, but also takes the unexpected paths towards future development. The company strives to maintain the market leader position in high pressure hydraulics and intends to become a world leader in the Plug-In technology for medium pressure hydraulic applications.

The Business Intelligence system that Cejn is using is simply Excel, which may come as a surprise for such a large company. Excel is a system written and distributed by Microsoft. It features calculation, graphing tools, pivot tables, and a macro programming language called Visual Basic for Applications. Excel uses a grid of cells arranged in numbered rows and letter-named columns to organize data. It even now comes with a Business Intelligence add-in (www.office.microsoft.com).

Cejn also uses Excel as a CRM system. The reason they use Excel is because it is simple to use and they have knowledge about it which means they don't need to put effort and time to acquire the skill to use another system. Cejn is satisfied with the system and does not want to change to another software. They would like to change to another system if the company grew bigger but right now they don't have any plan to expand.

\subsection{Company 5: Matthews Swedot AB}

Matthews Swedot AB was founded in 1850. The company works with custom marking solutions and standardized marking solutions for various industries, such as marking of milk cartons. They also offer solutions for industries that require extra security, such as anti-counterfeit marking and security marking, for example the pharmaceutical industry. The company is American owned and it is also here that they have their headquarter. Matthews Swedot AB has 41 employees in Sweden and the company is represented in countries such as Germany, France and Australia.

The company uses a business intelligence software system called Caesar CRM. The system is suited for large companies and offers solutions for sales, marketing and management amongst other functions (http://www.caesarcrm.com).
According to the contact the enterprise use the system to manage clients and record information about what the customers bought, as well as information on service visits. It can be likened by a sort of customer journal. The contact says that the reason for the choice of this system is because it is easy to use. The company has no plans to change the system because they are satisfied with how it works. The interviewee says that it is an efficient system that is adaptable to the company, but that the price is a little bit too high.

\subsection{Company 6: European Furniture Group}

European Furniture Group made its first Windsor chair in 1885 in Tranås, Sweden. Since then the company has grown into an international company that manufactures office furniture with a turnover exceeding 1000 million SEK in year 2010. The corporation has 540 employees of which 300 works in Sweden. Their production, which takes place in Sweden, Denmark and Finland, are driven by customer needs, which requires a functioning business intelligence software system. The company supplies more than 2000 complete workplaces, within the standard range, every week and most of them are ordered directly from the customer.

According to the contact the company has just replaced its old business intelligence software system which is called Sales Maker with Microsoft Dynamics CRM. The contact says that Microsoft Dynamics CRM basically is a CRM system, but that they also use it to make competitor analysis, manage products and information on quotes sent to customers.

The contact also said that the company uses Microsoft Dynamics CRM for the reason that it is easy to work with and because it is compatible with Microsoft Outlook, but also because it is suitable for the company's size. Furthermore, the interviewee consider that the system is efficient and user friendly. The company is also pleased with the system and believes that it is adaptable to their business needs, but that the price is too high.

\subsection{Company 7: VisioSign Sverige AB}

VisioSign has existed in Sweden for almost two years. It is a subsidiary of parent company VisioSign A / S, founded in 1999 in Denmark. VisioSign is a company with a focus on internal communications and digital signage. The main product is a software called Info Board. It can be divided into several different fields where you can link different information sources depending on what the customer wants. All solutions VisioSign 
makes are custom made and the company puts time to keep personal contact with existing customers. Thus the software is to be rented while the hardware is bought off by the customer.

There are only two people and a temporary assistant who works at the company in Sweden. But there are about 300 employees who work at subsidiary companies and mother companies. The subsidiary's turnover is about two million, and there is a limit to what information they have as the company is newly established in Sweden.

VisioSign uses a Business Intelligence system that is called Insightly. Insightly is a web based Customer Relationship and Project Management system. Insightly is integrated with Google Docs, Gmail and Google Calendar. The system uses Google Apps for login and authentication, so the user does not need to remember multiple passwords. Insightly is a tool for the vital task of managing the company's contacts and related organisations, partners, vendors and suppliers. The user can see everything about a contact on one page. Insightly also links each contact to the people and organisations around them - showing the relationships between contacts and employers, partners, suppliers, competitors, and co-workers (http://www.insight.ly).

VisioSign chose Insightly because the system meets the company's requirements. They also chose it because it is web based and inexpensive. VisioSign is satisfied with the system and does not want to change to another one. The cost for the system is reasonable from the company's point of view. They also think that the system is effective, user-friendly and adaptable.

\subsection{Company 8: Creative Tools}

Creative Tools $\mathrm{AB}$ operates as a department of a design and media company. It was established as an independent company in 2004. Originally Creative Tools AB was a corporation between two companies: Enthed Animation and Opus Media Tech. The company's customer database, expertise, partnership and business relationships in the industry, was established early in the 90's. Creative Tools AB sells products and services for the production of 3D animation, visualization, and video. The company is owned and operated by Paulo Kiefer (CEO) and Mona Kiefer (marketing manager). The company offers its customers computer graphics software and hardware for their needs. Creative Tools $\mathrm{AB}$ also offer education in computer graphics applications, and various production techniques online.
The company's customers are game developers, architects, photographers, and visualization companies, animators, designers, interior design firms and advertising agencies. Their customers range from private individuals, students, freelancers, to big international companies (http://www.creativetools.se).

The company's turnover in 2010 was 18329 million SEK with a profit of 614000 SEK. Their turnover has been increasing steadily since the company was established.

Creative Tools $\mathrm{AB}$ uses a Business Intelligence system called Vtiger. Vtiger is a CRM system which "is a community-driven, fully open source, CRM software. It enables small businesses manage leads, sales opportunities, quotes, invoices, support tickets, knowledge base, inventory and more. Vtiger CRM is used every day by over one hundred thousand businesses worldwide" (http://www.vtiger.com).

The reason Creative Tools $\mathrm{AB}$ uses Vtiger is because it's free, complete and adaptive. They are satisfied with the system and have no need to change to another one. They give the system a four grade for its effectiveness and user-friendliness. The company has a positive attitude towards the system and is satisfied with it.

\section{Analysis}

Theory states that companies use BIS in different areas within the organization. This means that not only top management can benefit from the BIS, but that also management lower down in the hierarchy can use this tool in order to access information and make better and quicker decisions (Mohamed, Philip \& Michael, 2008). This fits with the findings in this study. We found out that most of the companies we have been in contact with uses BIS for managing clients, to get consolidated information in a quick and easy way. In order to do this you need to have an effective system. As can be seen in the table below and from the interviews we found that Monitor and Microsoft Dynamics CRM, which is used by Tidbecks and EFG, is the most effective systems among the eight different systems we received information about, according to the companies themselves. Both companies rated the effectiveness of the systems with the highest grade. They stated that their systems help them significantly when handling information about their customers. The systems which have been graded lowest is the system Pyramid, which is used by Kungsäter Industri and Excel which is used by Cejn. Further, we can see a correlation between how effective and how user-friendly the systems 
are. The more efficient the system is the higher the companies valued the ease of use and vice versa. The only company that deviates from this is Cejn which stated that Excel is average when it comes to effectiveness but exceptional when it comes to user-friendliness. With MS Excel there is an add-in called PowerPivot which enhances its Business Intelligence capabilities.

In order to move forward in the research of Business Intelligence it has been suggested that there is a need to evaluate the different components of a BIS. One area that can be analyzed, for example, is if the system is easily integrated with other systems (compatibility). A Company should evaluate their potential BIS to see if the system is well suited for the company's total IT solutions to achieve better support in its decisions (Ghazanfari, Jafari \& Rouhani, 2011). When we relate this with the companies that we have studied, we see that the concern mentioned above, that the system integrates easily with other systems, are taken into account. All of the companies except Kungsäter Industri think that their system is easily integrated with the existing systems in the company. There is going to be other systems that are better suited for the company. Today there are so many different Business Intelligence software systems that it is of value for all companies to evaluate the different components of a Business Intelligence system in regards to their total needs. By doing this, the company can see if they are using a system that suites their company's needs well and if the system used is worth keeping.

By looking at the table below, which consists of factors that could be analyzed when evaluating the system and the values each company have accorded to their own system, we see that there are companies in this study that can benefit from reevaluating their system.

\begin{tabular}{|l|l|c|c|c|c|c|l|}
\hline Company & System & Efficiency & $\begin{array}{l}\text { User } \\
\text { friendliness }\end{array}$ & $\begin{array}{l}\text { Satisf- } \\
\text { action }\end{array}$ & Price & $\begin{array}{l}\text { Adapt- } \\
\text { ability }\end{array}$ & Tot: \\
\hline Kungsäter Industri & Pyramid & 3 & 3 & 3 & 2 & 2 & 2.6 \\
\hline Tidbecks & Monitor & 5 & 5 & 5 & 4 & 5 & 4.8 \\
\hline Evaldssons & Visma & 4 & 4 & 4 & 4 & 4 & 4.0 \\
\hline Cejn & Exell & 3 & 5 & 4 & 5 & 4 & 4.2 \\
\hline Matthews Swedot AB & Ceasar & 4 & 3 & 4 & 3 & 4 & 3.6 \\
\hline EFG & $\begin{array}{l}\text { Microsoft } \\
\text { Dynamics } \\
\text { CRM }\end{array}$ & 5 & 5 & 5 & 4 & 5 & 4.8 \\
\hline VisioSign & Insightly & 4 & 4 & 4 & 5 & 4 & 4.2 \\
\hline Creative Tools & Vtiger & 4 & 4 & 4 & 5 & 5 & 4.4 \\
\hline
\end{tabular}

Table 1: Companies and Business Intelligence systems evaluations

\section{Conclusion}

Business intelligence software systems is still a relatively unknown term in Sweden and most of the companies we have been in contact with have little knowledge about the term. We noticed that companies better understand what we speak about when we reformulate the term to "decision support" or "business analysis". In further research it may be interesting to look into why companies find certain business intelligence software systems effective (underlying factors). It may help further researchers in their work to get more accurate answers if they reformulated the concept of Business Intelligence into a language that people are more familiar with from the start. We have seen that all of the companies we have been in contact with use different business intelligence software systems without knowing that the systems they use falls under the umbrella Business Intelligence.

We have also seen that most companies are in great need of their existing systems, to create value added and simply to compete. The systems help them in their daily work, especially when it comes to managing information about their customers. The survey created a better understanding for some of 
the values of the systems. We see that the companies with the lowest average value are Kungsäter Industri and Matthews Swedot AB. Both of these companies would be advised to do a more extensive evaluation of their systems to see if there is another system on the market that creates more value.

Considering how many different systems that exist and how much they differ from each other, it is important to possess knowledge of the different systems in order to find out which of them are best suited for a specific company. The companies we studied have found some factors that are important to them in their choice of system. This should be of value for developers and sales people. We have found that features such as efficiency, simple concepts and adaptability of the system are of importance. It is of value to possess a system that is simple to learn and understand. Because BI systems are highly complex it is also important for a company to find people that already have knowledge of different systems when recruiting new employees, especially as it seems that new people often bring with them a change in BIS systems.

We see that the aspects of different Business intelligence systems are very different and that their degree of sophistication is different, to the point where most systems used cannot be called BI systems, but are merely simpler forms of "decision support". This is of particular concern for SMEs.

\section{References}

Cepeda G., Martin D. (2005). Guides and criteria for achieving quality in qualitative research. Management Decision, 851876.

Elbashir, M. Z., Collier, P. A., \& Davern, M. J. (2008). Measuring the effects of business intelligence systems: The relationship between business process and organizational performance. International Journal of Accounting Information Systems, 9(3), 135-153.

Ghazanfari M., Jafari M. \& Rouhani S. (2011). A tool to evaluate the business intelligence of enterprise systems. Scientia Iranica, Transactions E: Industrial Engineering, 1-11.

Gincel, R. (2005). Trickle-Down: Business Intelligence. InfoWorld, 27(17), 47-50.

Greengard, S. (1999). Mine your corporate data with business intelligence. Workforce Management, 78(1), 103-104.

Hannula, M., \& Pirttimaki, V. (2003). Business intelligence empirical study on the top 50 Finnish companies. Journal of American Academy of Business, Cambridge , 2(2), 593-599.
Karim, A. J. (2011). The Value Of Competitive Business Intelligence System (Cbis) To Stimulate Competitiveness In Global Market. International Journal of Business and Social Science, 2(19), 1-9.

Klein, G. (1999). User perception of expert system advice. The Journal of Systems and Software, 48(2), 155-161.

Klepic, Z. (2004). The influence of business intelligence on the business success of medium and large companies. An Enterprise Odyssey. International Conference Proceedings, 705-720.

Lönnqvist, A., \& Pirttimäki, V. (2006). The Measurement of Business Intelligence. Information Systems Management, 23(1), 32-40.

Mikroyannidis, A., \& Theodoulidis, B. (2010). Ontology management and evolution for business intelligence. International Journal of Information Management, 30(6), 559-566.

Mohamed Z. E., Philip A. C. \& Michael J. D. (2008). Measuring the effects of business intelligence systems: The relationship between business process and organizational performance. International Journal of Accounting Information Systems, 135-153.

Onwuegbuzie A. J., Johnson R. B. \& Collins K. M. T. (2009). Call for mixed analysis: A philosophical framework for combining qualitative and quantitative approaches. International Journal of Multiple Research Approaches, 114-139.

Sabanovic, Adis, Solberg Søilen, K. (2012). Customers' Expectations and Needs in the Business Intelligence Software Market. Journal of Intelligence Studies in Business, Vol 2, No 1, pp. 5-20

Xu, M., Ong, V., Duan, Y., \& Mathews, B. (2011). Intelligent agent systems for executive information scanning, filtering and interpretation: Perceptions and challenges. Information Processing \& Management, 47(2), 186-201. 